\title{
Research note: The Polarization of Trust in the European Parliament, 2002 - 2016
}

\author{
Paul C. Bauer \& Davide Morisi ${ }^{1}$
}

First version: $16^{\text {th }}$ of July 2020

\begin{abstract}
Scholars usually investigate how average levels of trust in EU institutions vary across countries and over time. Focusing on mean levels, however, ignores distributional properties that might be equally relevant for institutional legitimacy and, more broadly, democratic stability. In this study we investigate how the distribution of trust in the European Parliament (EP) has changed over time and across EU member states. Drawing on pooled cross-sectional data from the European Social Survey for the period 2002-2016, we find that confidence in the EP has not only declined over time but also polarized, since citizens have increasingly moved away from the "average citizen”. This polarizing trend has occurred especially in peripheral EU member states that suffered the most from the economic crisis. Furthermore, we find that trust has polarized especially among the young versus the elderly and the employed versus the unemployed. These findings have implications for EU institutions, whose legitimacy might be eroded in a highly polarized society.
\end{abstract}

\footnotetext{
${ }^{1}$ Paul C. Bauer: Mannheim Centre for European Social Research (MZES), @p c bauer, mail@paulcbauer.eu; Davide Morisi: Collegio Carlo Alberto, Turin, @dmorisi, davide.morisi@carloalberto.org;
} 


\section{Introduction}

Declining trust in democratic institutions has been a common concern of researchers over the last few decades. Accumulating evidence indicates that, on average, citizens' confidence has declined with respect to not only national institutions, including national governments (Dalton, 2005; Hobolt \& Vries, 2016; Jurado \& León, 2017; Norris, 1999; Pharr \& Putnam, 2000; Warren, 1999, final chapter), but also supranational institutions, such as the European Union (Armingeon \& Ceka, 2014; Armingeon \& Guthmann, 2014; Cramme \& Hobolt, 2014; Dotti Sani \& Magistro, 2016; Ehrmann et al., 2013; Roth et al., 2013). If citizens lose confidence in fundamental democratic institutions, the stability and legitimacy of democratic regimes might be at risk.

Yet, what could also pose a potential threat to stability is a situation in which political trust polarizes, that is, when citizens are moving increasingly "far apart" in their support for institutions. While research has commonly focused on changes in average levels of political trust (for a recent exception, see Hetherington \& Rudolph, 2015), the distribution of trust levels among citizens has not received scholarly attention, despite the relevant consequences that polarized (or non-polarized) distributions might have for institutional legitimacy. In this study we aim to fill this gap by focusing on how the distribution of trust in the European Parliament (EP) has changed over time and across countries.

We focus on the EP — a symbolic institution of the European Union — both for a methodological reason, because it allows us to conduct a comparative analysis across several countries, andmost importantly-for a substantial reason, since we expect that the distribution of political trust has changed following the economic crisis of 2008-2009. Building on evidence by Dotti Sani \& Magistro (2016) that the crisis has increased the gap between better-off and worse-off socioeconomic groups, we expect that trust in the EP has not only declined over time but also polarized, especially in peripheral EU member states that suffered the most from the consequences of the economic crisis. We therefore aim to address the following question: Has trust in the European Parliament polarized over time, and, if so, to what extent?

Investigating the distribution of trust levels proves relevant not only from a methodological perspective but also from a substantial one, since "distributional properties may have important consequences for political conflict and change” (DiMaggio et al., 1996, p. 692). A society with a high level of fractionalization and polarization may be particularly prone to inter-group conflict (Esteban \& Ray, 2008) and political conflict (Baldassarri \& Gelman, 2008). In the case of political trust, polarization may erode the legitimacy of democratic institutions that rely on a certain degree of support within the population. The polarization of trust might be problematic especially for a relatively "young" institution such as the European Union, which needs to challenge a supposed democratic deficit, as some scholars have argued (see, for example, Follesdal \& Hix, 2006).

Drawing on pooled cross-sectional data from the European Social Survey for the period 20022016, we find that trust in the European Parliament has not only declined over time but also polarized. This polarizing trend has occurred especially in peripheral EU member states that suffered the most from the economic crisis, and, allegedly, from the EU's austerity measures. When we compare different socioeconomic groups, we find that trust has polarized especially among the young versus the elderly, the employed versus the unemployed, and, to a lesser extent, those with high income versus those with low income. 
In addressing our research question, we make two major contributions. From a theoretical perspective, we contribute to the debate on how to define and measure polarization. Which characteristics of a distribution reflect the idea of polarization is still being discussed (Esteban \& Ray, 2008; Lelkes, 2016; Park, 2018), and scholars often reach opposite conclusions depending on how they measure polarization. Second, from a substantial point of view, we contribute to the debate on how support for the European Union has changed following the economic crisis. While previous studies have investigated whether trust in the government has polarized in the United States (Hetherington \& Rudolph, 2015), to our knowledge, this is the first study to explore the polarization of trust in the EU across countries over time. By departing from a standard focus on mean values, we aim to encourage researchers to consider also distributional properties of trust indicators that might have equally relevant consequences for support for institutions, and ultimately, for democratic stability.

In the next sections, we first present our theoretical framework and hypotheses, followed by a discussion on how to conceptualize and measure polarization. We then present our data and the results. In the conclusion, we underline some limitations of the analysis and highlight some implications of our findings for research on polarization, political trust, and support for EU institutions.

\section{Trust in the EU and the economic crisis}

Political trust is often defined as a truster's expectation that a political actor will act in his/her interest (Levi \& Stoker, 2000). Following this notion, we conceive of trust in European institutions as a citizen's belief that he/she can rely on the beneficial actions of the EU (Armingeon \& Ceka, 2014, p. 88). In this sense, our notion of trust represents an indicator of Easton's idea of diffuse support for a political system (Easton, 1975).

Although the EU enjoyed a period of relatively stable support after the mid-1990s (Hix 2008: 52), recent studies have shown that the average level of trust in European institutions has decreased across several countries over the last decade (e.g. Dotti Sani \& Magistro, 2016, p. 255; Armingeon \& Ceka, 2014). Scholars argue that one of the reasons for this decline is the austerity policies that the EU imposed (in tandem with the IMF) on several member states following the economic crisis (Ehrmann et al., 2013). According to Roth et al. (2013), a significant decline in trust in EU institutions occurred especially in peripheral Eurozone countries-including Spain, Greece, Portugal, and Ireland — which experienced a large increase in unemployment rates during the crisis.

According to another perspective, "support for the EU is derived from evaluations of national politics and policy, which Europeans know far better than the remote political system of the EU” (Armingeon \& Ceka, 2014, p. 83). In this sense, confidence in European institutions is a function of evaluations of national-level institutions. Thus, declining trust in the EU would be the consequence of citizens losing confidence in their national governments, which primarily took the blame for the economic crisis (see also Armingeon \& Guthmann, 2014).

Regardless of whether trust in European institutions should be considered as either a "first-order" or a "second-order" type of trust derived from national institutions, these studies suggest that, following the economic crisis, trust in the EU might have also polarized, as long as the loss of confidence occurred unevenly within the population of EU member states. Indeed, evidence by 
Dotti Sani \& Magistro (2016) confirms that the gap in support for the European parliament between high and low social strata has widened after the economic crisis, especially among peripheral EU member states, namely Portugal, Italy, Ireland, Cyprus, Greece, and Spain. The argument is that the crisis drove apart different segments of the populations by worsening the conditions not of all European citizens indistinctly, but mostly of the "losers" of globalization (Kriesi et al., 2012).

Based on this evidence, therefore, we hypothesize that the overall level of polarization of trust in the European Parliament has increased across Europe over time (H1). While we expect a general trend of increasing polarization, we hypothesize that an increase in polarization has taken place especially in peripheral EU member states (H2).

While an investigation of overall levels of polarization is informative, we are still left with the question of who polarized. Here, we move to the conceptual notion of between-group polarization. Classic explanations of political trust rely on socioeconomic dimensions such as income and education. For instance, Dalton (2005, p. 139) suggests that "increasing inequality in economic conditions may lead to growing cynicism among those at the lower end of the social status ladder”. Hence, we would expect that it is along those dimensions that individuals have polarized especially in the wake of the crisis, i.e., that polarization occurs between individuals belonging to clusters of less and more privileged social strata.

Dotti Sani \& Magistro (2016, p. 260) identify four clusters of “less privileged social strata”, including the poorly educated, those with perceived lower levels of income, the unemployed and the retired, and the youth and the elderly. ${ }^{2}$ While it seems reasonable to expect that the crisis affects citizens differently depending on the level of education, income, and work status, the role of age appears more complicated. Although both young and elderly people suffered from the crisis in terms of job loss and austerity measures, including pension cuts, the youth also represents the generation that has grown up and been socialized into the European Union (Grimm et al., 2018). Thus, we would expect trust in the EU to move towards opposite ends between the young and the elderly. Accordingly, we broadly hypothesize that polarization of trust in the European Parliament occurred between groups of less privileged and more privileged strata of society-in relation to education, income, and work status - and between the youth and the elderly (H3). Lastly, in line with the evidence mentioned above, we expect between-group polarization to be more pronounced in peripheral EU member states (H4).

\section{Conceptualizing and measuring the polarization of trust}

In a seminal article exploring whether public opinion polarized in the U.S. between the 1970s and the 1990s, DiMaggio and colleagues note that "[g]iven polarization's prominence in contemporary political discourse, the literature provides strikingly little guidance in defining it” (DiMaggio et al., 1996, p. 692). Twenty years afterwards, despite vast scholarly attention on the topic, the definition of polarization remains far from unequivocal. In a recent contribution, Lelkes

\footnotetext{
${ }^{2}$ Torcal (2014) suggests that an erosion of trust should not only be attributed to the economic crisis but might generally be due to citizens' perception that European institutions are unresponsive to their demands. We can imagine that such perceptions are more common among socially disadvantaged citizens.
} 
(2016) suggests that at least "four distinct manifestations of polarization have appeared in the public opinion literature - ideological consistency, ideological divergence, perceived polarization, and affective polarization” (p. 393). Each of these manifestations in turn has led scholars to derive often diverging conclusions about whether opinion polarization has actually increased or decreased over time (for a review, see Park, 2018). If one includes research that investigates the polarization of phenomena such as income, ethnic, religious, or geographic polarization, the population of measures to choose from grows quickly.

Broadly speaking, the level of polarization describes the degree to which individuals' positions on one or several scales are separated. However, the nature of this separation (or distance) is still subject to debate, and scholars disagree on the extent to which different characteristics of a distribution reflect the idea of polarization. Building on both contributions from sociology and political science, we rely on two different notions of polarization (Baldassarri \& Bearman, 2007; DiMaggio et al., 1996; Lelkes, 2016; Park, 2018).

The first notion refers to the "dispersion principle” (DiMaggio et al., 1996, p. 693), according to which a necessary condition for polarization to occur over time is that the distribution of opinions along a scale becomes more dispersed. In the case of political trust, a distribution becomes more scattered as some individuals display increasingly higher or lower levels of trust over time, while others either do not change their mind or move in the opposite direction. Building on DiMaggio et al. (1996) and in line with recent studies of opinion polarization (Park, 2018) and ideological polarization (Bischof and Wagner 2019), we use the variance of a standard 0-10 scale of trust in the European Parliament as a proxy for overall polarization. ${ }^{3}$ The formula is the following:

$$
v_{c t}=\frac{1}{n_{c t}} \sum_{i=1}^{n_{c t}}\left(x_{i c t}-\overline{x_{c t}}\right)^{2},
$$

where $v_{t c}$ is the value of the variance of trust in the European Parliament for countryc at yeart, $x_{i c t}$ is an individual $i$ 's level of trust in country $c$ at time $t, x_{c t}$ is the respective country mean of trust at time $t$, and $n_{c t}$ is the sample size (number of individuals) for country $c$ at time $t$. While being a crude proxy for polarization, the variance has the advantage of being easy to interpret: as individuals display levels of trust that are increasingly distant from the sample's mean, the value of variance (indicating the overall level of polarization) increases. Since the distance is squared, those far from the mean $x_{c t}$ carry more weight, thus capturing the idea that trust polarizes when more individuals show extremely high or low levels of confidence. ${ }^{4}$

The second notion refers to between-group polarization, namely the distance between two particular subgroups on a dimension of interest. In our case, we aim to determine the extent to which individuals belonging to different socioeconomic groups share the same degree of trust. While a common method would be to compare average levels of trust across socioeconomic

\footnotetext{
${ }^{3}$ For a distribution to polarize, both dispersion and bimodality need to increase. However, the literature does not seem to offer a reliable measure of bimodality. Both the kurtosis and the bimodality coefficient, which have been proposed as possible measures, suffer from serious limitations (see, e.g., Park, 2018, p. 1778). For these reasons, we consider only the dimension of dispersion.

${ }^{4}$ In this sense, the variance is preferable to the standard deviation, because the standard deviation, being the square root of the variance, does not attribute disproportionately higher weight to extreme values.
} 
groups, “a difference-of-means test by itself is not enough to draw conclusions about polarization” (Levendusky \& Pope, 2011, p. 230). This is because similar mean differences can be the result of very different distributions. Following recent advances in the study of polarization (see Lelkes, 2016; Levendusky \& Pope, 2011; Park, 2018; Schmid \& Schmidt, 2006), we therefore rely on the overlap coefficient as a measure of between-group polarization. The overlap coefficient represents "the common area under two probability densities" (Schmid \& Schmidt, 2006, p. 1583) and can be used to measure the degree of overlap or common ground between two groups:

$$
1-\frac{1}{2} \int_{-\infty}^{+\infty}|f(x)-g(x)| d x
$$

where $f(x)$, in this case, represents the distribution of trust among group 1, and $g(x)$ represents the distribution of trust among group 2. As two groups diverge in their distribution of trust, the overlap coefficient-i.e., the common ground between the two groups-decreases, thus indicating increased polarization.

\section{Data and models}

We rely on data from eight waves of the European Social Survey (ESS) for the period 20022016. We exclude countries that were not member of the EU at the time the surveys were conducted (such as Croatia), and countries for which we do not have at least one data point during or after the crisis in 2008 (such as Luxembourg). This leaves us with a total of 25 EU members states, as summarized in Table 1.

To measure trust, we rely on a question that asks how much the respondents personally trust the European Parliament on a standard scale ranging from 0 "no trust at all" to 10 "complete trust" (for question wording, see Table A1). It is important not to "over-theorize" the actual responses to these scales, since individuals might answer based on considerations that are at the "top of their head" when they are surveyed (Zaller, 1992). Studies have shown that there is considerable variation in such general trust questions (Nannestad, 2008). In other words, we assume that individual locations on the trust scale reflect a simplistic cognitive process and that answers on the scale may reflect a number of considerations that come to participants' mind when they are asked the survey question.

Table 1: Data across countries and across time

\begin{tabular}{lccccccccc}
\hline Nr. & Country & 2002 & 2004 & 2006 & 2008 & 2010 & 2012 & 2014 & 2016 \\
\hline 1 & Austria & 0 & 0 & 0 & & & & 0 & 0 \\
2 & Belgium & 0 & 0 & 0 & 0 & 0 & 0 & 0 & 0 \\
3 & Bulgaria & & & 0 & 0 & 0 & 0 & & \\
4 & Cyprus & & & 0 & 0 & 0 & 0 & & \\
5 & Czechia & 0 & 0 & & 0 & 0 & 0 & 0 & 0 \\
6 & Denmark & 0 & 0 & 0 & 0 & 0 & 0 & 0 & \\
7 & Estonia & & 0 & 0 & 0 & 0 & 0 & 0 & 0 \\
8 & Finland & 0 & 0 & 0 & 0 & 0 & 0 & 0 & 0 \\
9 & France & 0 & 0 & 0 & 0 & 0 & 0 & 0 & 0
\end{tabular}




\begin{tabular}{lccccccccc}
10 & Germany & 0 & 0 & 0 & 0 & 0 & 0 & 0 & 0 \\
11 & Greece & 0 & 0 & & 0 & 0 & & & \\
12 & Hungary & 0 & 0 & 0 & 0 & 0 & 0 & 0 & 0 \\
13 & Ireland & 0 & 0 & 0 & 0 & 0 & 0 & 0 & 0 \\
14 & Italy & 0 & 0 & & & & 0 & & 0 \\
15 & Latvia & & & 0 & 0 & & & & \\
16 & Lithuania & & & & & 0 & 0 & 0 & 0 \\
17 & The Netherlands & 0 & 0 & 0 & 0 & 0 & 0 & 0 & 0 \\
18 & Poland & 0 & 0 & 0 & 0 & 0 & 0 & 0 & 0 \\
19 & Portugal & 0 & 0 & 0 & 0 & 0 & 0 & 0 & 0 \\
20 & Romania & & & 0 & 0 & & & & \\
21 & Slovakia & & 0 & 0 & 0 & 0 & 0 & & \\
22 & Slovenia & 0 & 0 & 0 & 0 & 0 & 0 & 0 & 0 \\
23 & Spain & 0 & 0 & 0 & 0 & 0 & 0 & 0 & 0 \\
24 & Sweden & 0 & 0 & 0 & 0 & 0 & 0 & 0 & 0 \\
25 & United Kingdom & 0 & 0 & 0 & 0 & 0 & 0 & 0 & 0 \\
\hline
\end{tabular}

To test H1, we calculate the variance of the trust scale for each country at each time point and regress it on a year variable to detect whether trust in the EP has polarized over time (in terms of increased variance). We repeat the same operation using the mean of the trust scale to test whether trust has also declined in the same time period. To test $\mathrm{H} 2$, we add an interaction between the year variable and a "periphery" indicator, taking the value of 1 if the country is from the peripheral area—including Portugal, Italy, Ireland, Cyprus, Greece and Spain—or a value of 0 otherwise.

In alternative specifications, we rely on the weighted mean and variance (see Table A3), use a pre-post crisis indicator for the time variable (see Table A4), and control for GDP growth, unemployment rate, and trust in national parliaments (see Table A5 and A6).

To identify whether between-group polarization has increased over time (H3 and H4), we first calculate the overlap coefficient for each country at each time point for each pair of socioeconomic groups.

We, then use it as the outcome in linear regression models. Based on our theoretical background, we group respondents along the following dimensions: education, perceived living on income, work status, and age (See Table A1 for question wordings and coding decisions). To test H4, we add an interaction term between the time variable (years) and the "periphery" indicator. Lastly, we replicate the analysis of between-group polarization using the classic between-group mean differences instead of the overlap coefficient (see Table A7). 


\section{Empirical results}

\section{Overall polarization}

Figure 1 visualizes all data points underlying our analysis. For each country, we show changes over time for both the mean and the variance of trust in order to compare the two phenomena. As Figure 1 reveals, there is large variation across European countries regarding both average levels of trust and the variance. ${ }^{5}$ Furthermore, the analysis indicates that mean and variance tap into different dimensions not only conceptually but also empirically, since they are only weakly correlated. ${ }^{6}$ We can also observe that in some cases - such as Cyprus, Italy, Portugal, and Spain - the two dimensions move in opposite directions in the period after the crisis, thus indicating that trust in the EP did not decline uniformly within the populations of these countries.

In Table 2 we display the results from simple linear regression models in which we pooled together all our data points, controlling for country fixed effects. The results from Models 1 and 2 confirm existing evidence that trust in the EP has declined over time-a decrease of around half a point on a 0-10 scale over the entire period of time (Model 1). Moreover, the negative interaction in Model 2 indicates that the decline has been more pronounced in peripheral EU countries.

Table 2: Changes in trust in the EP over time

\begin{tabular}{lcccc}
\hline & \multicolumn{3}{c}{ Outcome: Trust in the EP } \\
\cline { 2 - 5 } & M1 & Mean & M3 & M4 \\
\hline Year (0-14) & $-0.04^{* * *}$ & $-0.03^{* * *}$ & $0.04^{* * *}$ & $0.02^{*}$ \\
& $(0.01)$ & $(0.01)$ & $(0.01)$ & $(0.01)$ \\
Periphery & & $1.16^{* * *}$ & & $-1.36^{* * *}$ \\
(0,1) & & $(0.24)$ & & $(0.28)$ \\
& & $-0.07^{* * *}$ & & $0.07^{* * *}$ \\
Year x & & $(0.02)$ & & $(0.02)$ \\
Periphery & $4.16^{* * *}$ & $4.06^{* * *}$ & $6.20^{* * *}$ & $6.30^{* * *}$ \\
Constant & $(0.18)$ & $(0.17)$ & $(0.21)$ & $(0.21)$ \\
\hline Observations & 159 & 159 & 159 & 159 \\
$\mathrm{R}^{2}$ & 0.64 & 0.68 & 0.81 & 0.83 \\
\hline Note: & & ${ }^{*} \mathrm{p}<0.05 ;{ }^{* *} \mathrm{p}<0.01 ;{ }^{* * *} \mathrm{p}<0.001$
\end{tabular}

\footnotetext{
${ }^{5}$ The Y-axis provides the values of both dimensions, but the underlying scales are different: the mean ranges from 0 to 10 , while the variance ranges from 0 to a hypothetical maximum of 25, which would be reached in the case of a completely bipolar distribution in which half of the population has no trust in the EP (value of 0 ) and the other half has complete trust (value of 10).

${ }^{6}$ The correlation between the two lies at 0.17 (2002), 0.06 (2004), 0.13 (2006), -0.24 (2008), -0.17 (2010), -0.26 (2012), -0.29 (2014), and -0.29 (2016).
} 
Data: European Social Survey, 2002-2016.

The models include country fixed effects.

Time variable rescaled so that year 2002 corresponds to value 0 .

Figure 1: Overall polarization of trust in the EP

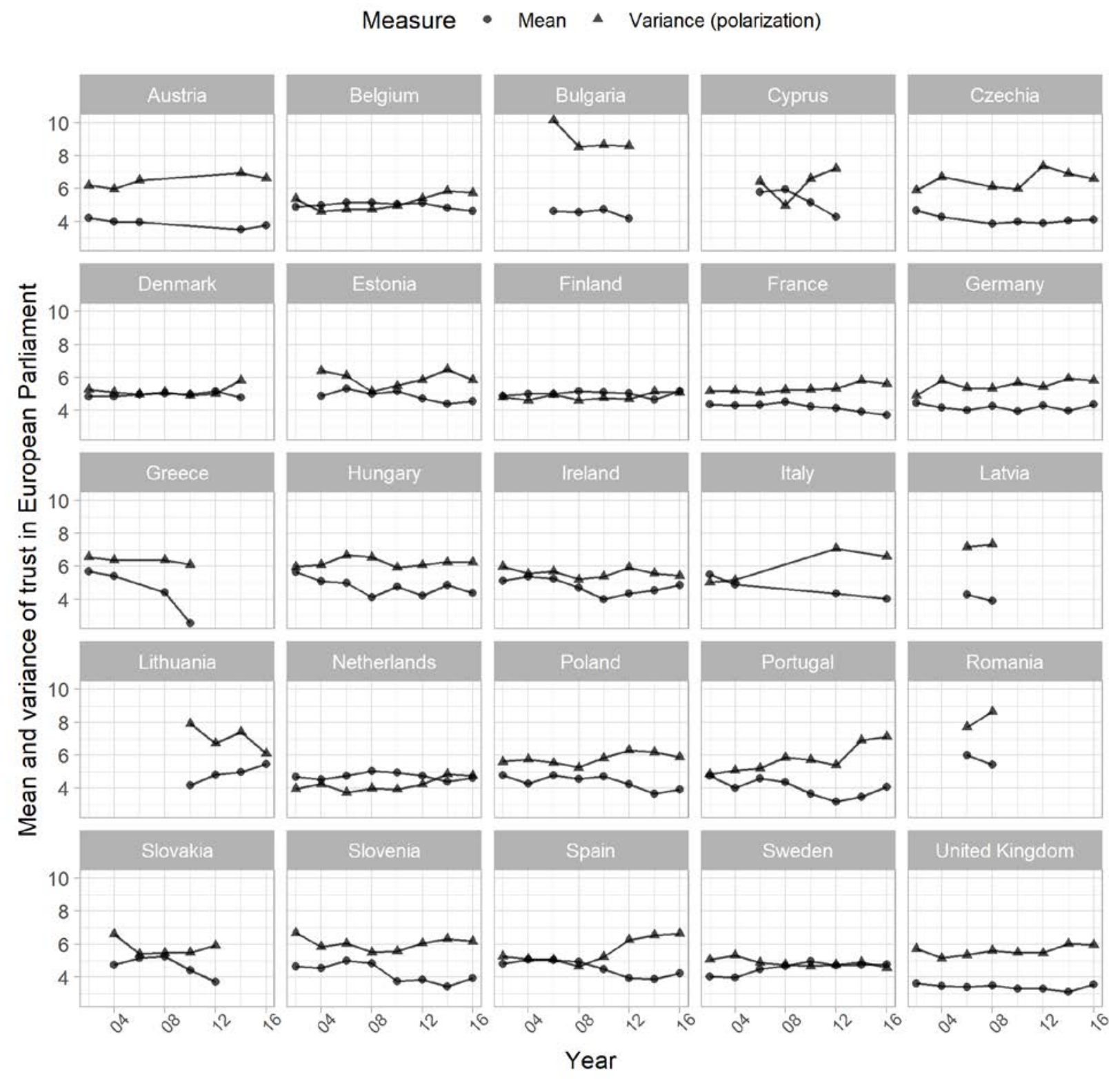

However, Models 3 and 4 reveal that confidence in the EP has also polarized. Model 3 shows that the distribution of trust has become more dispersed over time, since the variance of the responses to the trust question has increased from 2002 to 2016. This finding supports our hypothesis that the overall level of polarization of trust in the European Parliament has increased 
across Europe (H1). Furthermore, the positive and statistically significant interaction in Model 4 indicates that trust in the EP has polarized mostly in peripheral EU countries. Thus, we find evidence that the overall trend of polarization is more pronounced in countries that were hit hardest by the crisis (H2). Although the magnitude of these changes can be deemed small when we consider all EU countries, if we focus on peripheral countries instead, our results indicate a relatively substantial change. In this area of the EU, during the 2002-2016 period, trust decreased by 14 percentage points (1.4 points on a $0-10$ scale), and polarized by around 5 percentage points (an increase in the variance of 1.3 points on a $0-25$ scale).

When we run additional models using the weighted values of both mean and variance and controlling for GDP growth and unemployment rate, we obtain similar results (see Appendix A.3). Interestingly, as identified in previous research (Armingeon \& Ceka, 2014), the results hold also when we control for trust in national parliaments, even if confidence in national parliaments and trust in the EP are strongly correlated. ${ }^{7}$ Lastly, when we code the year variable as a pre-post crisis indicator, we find that both the decline in trust and the increase of polarization occurred in the period after the crisis, thus confirming our initial hypotheses (see Appendix A.3).

\section{Between-group polarization}

Next, we investigate whether trust in the EP has polarized as a result of different socioeconomic groups moving increasingly far apart. Figure 2 visualizes trends of between-group polarization, as measured by the overlap coefficient. Lower values on the Y-axis indicate lower overlap in terms of trust in the EP between the specified categories, thus corresponding to increasing polarization. Although we find variation over time, Figure 2 reveals also substantial variation across countries. At a first visual inspection, trust seems to have polarized especially between age groups and between employed versus unemployed citizens, at least in some countries-including Belgium, Germany, Portugal, Sweden, and the UK.

We subsequently pooled all data points and conducted linear regressions of overlap coefficients on time indicators, controlling for country fixed effects. The results in Table 3 confirm that the overlap between young and old people (Model 1) and between the employed and the unemployed (Model 5) regarding trust in the EP has decreased over time. In other words, polarization occurred along both age lines and work status categories. ${ }^{8}$ Regarding income (Model 3), the results indicate that trust has polarized also between low- and high-income groups, although the gap is smaller than the age gap, and statistically significant only at the 0.1 level. Contrary to our expectations, we do not find evidence that trust has polarized between citizens with low and high education (Model 7). Lastly, interaction models in Table 3 show that there are either no statistically significant interactions between the time variable and the "periphery" indicator or actually a positive interaction regarding the work status group.

\footnotetext{
${ }^{7}$ See Figure A2 for a visual trend, and Appendix A.3 for complete regression models.

${ }^{8}$ When we compare people aged 18-35 with people aged 36-64, we find a similar result, but not when we compare the latter with people aged 65 or above, thus indicating that it is mostly the young segment of the population that distanced themselves from the rest in terms of trust (see Table A7).
} 
Figure 2: Between-group polarization (overlap): time trend

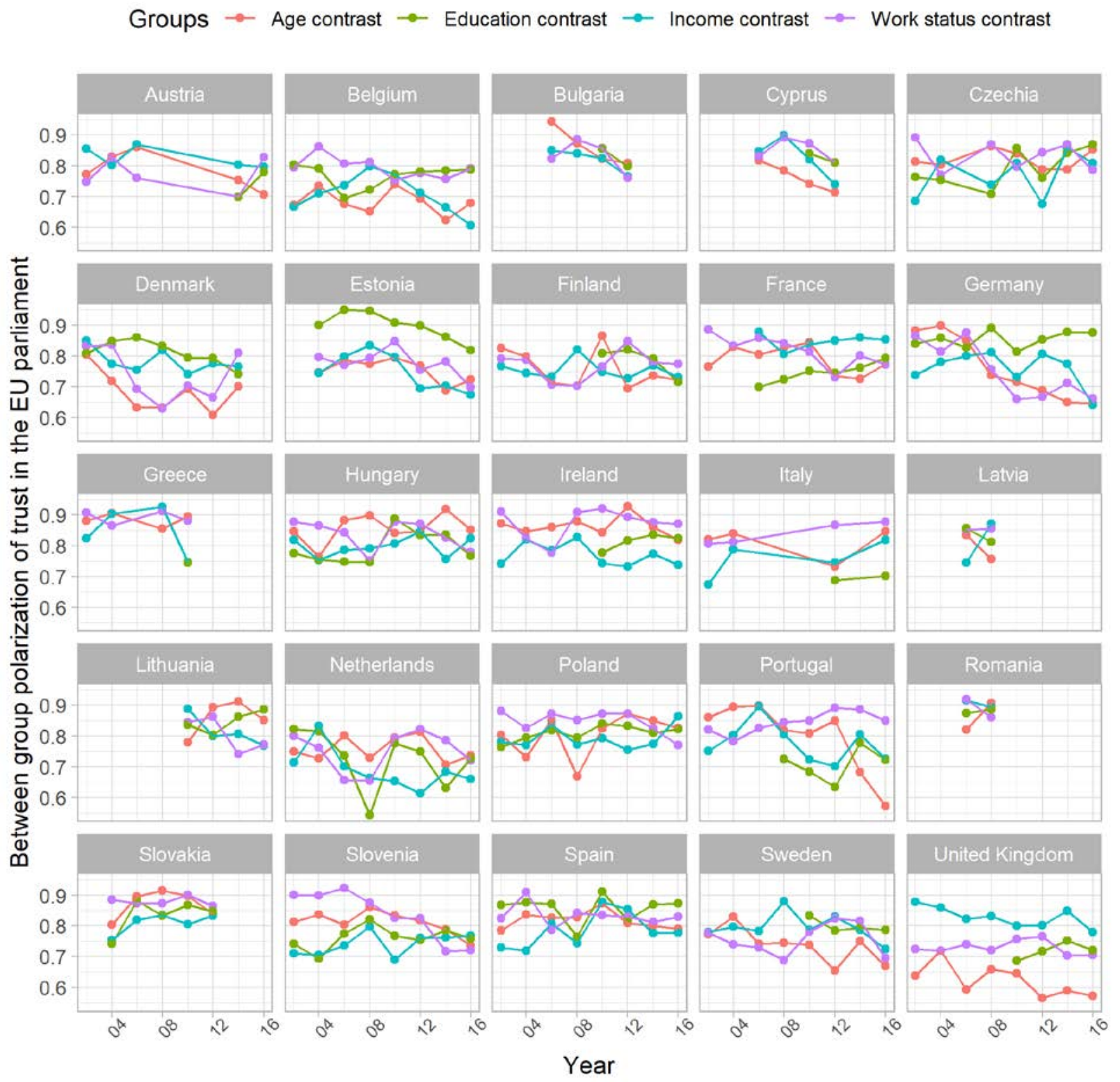

When we conduct an alternative analysis using the difference in average levels of trust between groups, we find further confirmation that the gap in trust in the EP between age groups, income groups, and work status categories has increased over time (cf. Table A7, Figure A3). These findings bring partial support for $\mathrm{H} 3$, since we find that trust in the EP has polarized between the young and the elderly, the employed and the unemployed, and, to a lesser extent, the low- and high-income earners. However, we cannot confirm our hypothesis (H4) that between-group polarization has occurred more strongly within the countries in the periphery of the EU. 
Table 3: Changes in between-group polarization (overlap) over time

\begin{tabular}{|c|c|c|c|c|c|c|c|c|}
\hline & \multicolumn{8}{|c|}{ Outcome: Overlap coefficient } \\
\hline & \multicolumn{2}{|c|}{ Age groups } & \multicolumn{2}{|c|}{ Income groups } & \multicolumn{2}{|c|}{ Work groups } & \multicolumn{2}{|c|}{ Educ. groups } \\
\hline & M1 & M2 & M3 & M4 & M5 & M6 & M7 & M8 \\
\hline Year $(0-14)$ & $\begin{array}{c}-0.005^{* * *} \\
(0.001)\end{array}$ & $\begin{array}{c}-0.004^{* * *} \\
(0.001)\end{array}$ & $\begin{array}{l}-0.002 \\
(0.001)\end{array}$ & $\begin{array}{l}-0.002 \\
(0.001)\end{array}$ & $\begin{array}{c}-0.003^{* *} \\
(0.001)\end{array}$ & $\begin{array}{c}-0.005^{* * *} \\
(0.001)\end{array}$ & $\begin{array}{c}0.001 \\
(0.001)\end{array}$ & $\begin{array}{c}0.001 \\
(0.001)\end{array}$ \\
\hline Periphery $(0,1)$ & & $\begin{array}{c}0.05 \\
(0.03)\end{array}$ & & $\begin{array}{l}-0.05 \\
(0.03)\end{array}$ & & $\begin{array}{c}0.02 \\
(0.03)\end{array}$ & & $\begin{array}{c}0.12^{*} \\
(0.05)\end{array}$ \\
\hline $\begin{array}{l}\text { Year x } \\
\text { periphery }\end{array}$ & & $\begin{array}{l}-0.002 \\
(0.002)\end{array}$ & & $\begin{array}{c}0.002 \\
(0.002)\end{array}$ & & $\begin{array}{l}0.01^{* *} \\
(0.002)\end{array}$ & & $\begin{array}{c}0.001 \\
(0.003)\end{array}$ \\
\hline Constant & $\begin{array}{l}0.81^{* * *} \\
(0.02)\end{array}$ & $\begin{array}{l}0.81^{* * *} \\
(0.03)\end{array}$ & $\begin{array}{l}0.84^{* * *} \\
(0.02)\end{array}$ & $\begin{array}{l}0.84^{* * *} \\
(0.02)\end{array}$ & $\begin{array}{l}0.79^{* * *} \\
(0.02)\end{array}$ & $\begin{array}{l}0.80^{* * *} \\
(0.02)\end{array}$ & $\begin{array}{l}0.73^{* * *} \\
(0.04)\end{array}$ & $\begin{array}{l}0.73^{* * *} \\
(0.04)\end{array}$ \\
\hline Observations & 159 & 159 & 157 & 157 & 159 & 159 & 126 & 126 \\
\hline $\mathrm{R}^{2}$ & 0.65 & 0.65 & 0.46 & 0.47 & 0.52 & 0.56 & 0.60 & 0.60 \\
\hline Note: & $\mathrm{Da}$ & $\begin{array}{r}\text { uropean } S \\
\text { Tim }\end{array}$ & e variable & rescaled & $\begin{array}{l}\text {-2016. The } \\
\text { so that yea }\end{array}$ & $\begin{array}{l}{ }^{*} \mathrm{p}<0.05 ; \\
\text { e models in } \\
\text { ir } 2002 \text { corr }\end{array}$ & $\begin{array}{l}<0.01 \text {; } \\
\text { lude cou }\end{array}$ & $\begin{array}{r}{ }^{*} \mathrm{p}<0.001 \\
\text { try fixed } \\
\text { effects. } \\
\text { value } 0 .\end{array}$ \\
\hline
\end{tabular}




\section{Conclusion}

Over the last few decades, scholars have raised concerns about a decline of trust in democratic institutions in different regions of the world. We provide novel evidence that, during the last two decades, confidence in the European Parliament has not only declined but also polarized. European citizens have moved increasingly far apart in their support for the EP, and this polarizing trend has taken place especially in peripheral EU countries. Although we do not test causal explanations, we argue that one of the possible reasons underlying this polarizing trend concerns the economic crisis, which has increased the gap between different socioeconomic segments of the population (Cramme \& Hobolt, 2014; Dotti Sani \& Magistro, 2016).

Furthermore, we find that trust has polarized especially between the employed versus the unemployed, and between the young versus the elderly. The latter finding resonates with a recent analysis of the Brexit referendum, in which attitudes towards the European Union markedly diverged between younger and older segments of the population (Norris \& Inglehart, 2019). They highlight a generational cleavage in support for EU institutions that deserves more scholarly attention.

It is important to underline two limitations of our analysis. First, our measure of overall polarization provides only a proxy for polarization, since it does not fully capture the dimension of bimodality. As far as we are aware, there are no available measures that satisfactorily capture both dispersion and bimodality (Park, 2018). We therefore urge scholarly attempts to develop a more refined measure of polarization that combines both dimensions in one single indicator. Second, our analysis relies on pooled cross-sectional data, since there are no cross-country panel data available to study our questions. Thus, it might be that some of the differences we find may result from slightly different sample compositions over time.

Despite these limitations, our findings have relevant implications for the legitimacy of the European Parliament and, more broadly, the European Union. If such a polarizing trend continues in the future, EU institutions might find it increasingly challenging to harness support among European citizens, while political conflict may arise due to opposing views between different socioeconomic groups. From a normative perspective, if the aim is to maintain a healthy degree of support for EU institutions, European elites should attempt to not only revert the current trend of declining trust in EU institutions, but also close the gap between the youth and the elderly, and between better-off and worse-off social strata. 


\section{References}

Armingeon, K. \& Ceka, B. (2014). The loss of trust in the european union during the great. European Union Politics 15 (1): 82-107.

Armingeon, K. \& Guthmann, K. (2014). Democracy in crisis? The declining support for national. Eur. J. Polit. Res. 53 (3): 423-442.

Baldassarri, D. \& Bearman, P. (2007). Dynamics of political polarization. Am. Sociol. Rev. 72 (5): 784-811.

Baldassarri, D. \& Gelman, A. (2008). Partisans without constraint: Political polarization and trends in american public opinion. AJS 114 (2): 408-446.

Cramme, O. \& Hobolt, S.B. (2014). Democratic politics in a european union under stress. OUP Oxford.

Dalton, R.J. (2005). The social transformation of trust in government. International Review of Sociology 15 (1): 133-154.

DiMaggio, P., Evans, J. \& Bryson, B. (1996). Have american's social attitudes become more polarized? Am. J. Sociol. 102 (3): 690-755.

Dotti Sani, G.M. \& Magistro, B. (2016). Increasingly unequal? The economic crisis, social inequalities. Eur. J. Polit. Res. 55 (2): 246-264.

Easton, D. (1975). A re-assessment of the concept of political support. British journal of political science 5 (4): 435-457.

Ehrmann, M., Soudan, M. \& Stracca, L. (2013). Explaining european union citizens' trust in the european. Scand. J. Econ. 115 (3): 781-807.

Esteban, J. \& Ray, D. (2008). Polarization, fractionalization and conflict. Journal of Peace Research 45 (2): 163-182.

Follesdal, A. \& Hix, S. (2006). Why there is a democratic deficit in the EU: A response to. JCMS: Journal of Common Market Studies 44 (3): 533-562.

Grimm, R., Pollock, G., Ellison, M., Koronaiou, A., Lagos, E. \& Sakellariou, A. (2018). Attitudes towards the eu among young people in eastern germany, greece, and the uk: Em- bedding survey data within socio-historical context. In H. Pilkington, G. Pollock \& R. Franc (eds.), Understanding youth participation across europe: From survey to ethnography. London: Palgrave Macmillan UK.

Hetherington, M.J. \& Rudolph, T.J. (2015). Why washington won’t work: Polarization, political trust, and. University of Chicago Press.

Hobolt, S.B. \& Vries, C.E. de. (2016). Public support for european integration. Annu. Rev. Polit. Sci. 19 (1): 413-432.

Jurado, I. \& León, S. (2017). Economic crises and the nationalisation of politics. Eur. J. Polit. Res. 56 (4): 777-800.

Kriesi, H., Grande, E. \& Dolezal, M. and. (2012). Political conflict in western europe. Cambridge University Press.

Lelkes, Y. (2016). Mass polarization: Manifestations and measurements. Public Opin. Q. 80 (S1): 
$392-410$.

Levendusky, M.S. \& Pope, J.C. (2011). Red states vs. Blue states: Going beyond the mean. Public Opin. Q. 75 (2): 227-248.

Levi, M. \& Stoker, L. (2000). Political trust and trustworthiness. Annual Review of Political Science $3: 475-507$.

Nannestad, P. (2008). What have we learned about generalized trust, if anything? Annu. Rev. Polit. Sci. 11 (1): 413-436.

Norris, P. (1999). Critical citizens: Global support for democratic government. OUP Oxford.

Norris, P. \& Inglehart, R. (2019). Cultural backlash: Trump, brexit, and authoritarian populism. Cambridge University Press.

Park, B. (2018). How are we apart? Continuity and change in the structure of ideological disagreement in the american public, 1980-2012. Social Forces 96 (4): 1757-1784.

Pharr, S.J. \& Putnam, R.D. (2000). Officials’ misconduct and public distrust: Japan and the liberal.

Roth, F., Nowak-Lehmann D, F. \& Otter, T. (2013). Crisis and trust in national and european union institutions: Schmid, F. \& Schmidt, A. (2006). Nonparametric estimation of the coefficient of. Comput. Stat. Data Anal. 50 (6): 1583-1596.

Torcal, M. (2014). The decline of political trust in spain and portugal: Economic. Am. Behav. Sci. 58 (12): 1542-1567.

Warren, M.E. (1999). Democracy and trust. Cambridge, England: Cambridge University Press.

Zaller, J. (1992). The nature and origins of mass opinion. Cambridge University Press. 


\section{Online Appendix}

\section{Research note: The Polarization of Trust in the European Parliament}

Contents

A.1 Wording of questions and recoding $\quad 2$

A.2 Summary statistics 4

A.3 Alternative specifications: Overall polarization 5

A.4 Alternative specifications: Between-group polarization 10 


\section{A.1 Wording of questions and recoding}

Figure A1 provides the distributions of the original variables on which our grouping variables are based. We group individuals according to age, whether they live comfortably on their income, work status, and education. Table A1 outlines how we recoded the variables to build the contrasts and measure between-group polarization.

Table A1: Measures: wording and coding of survey questions

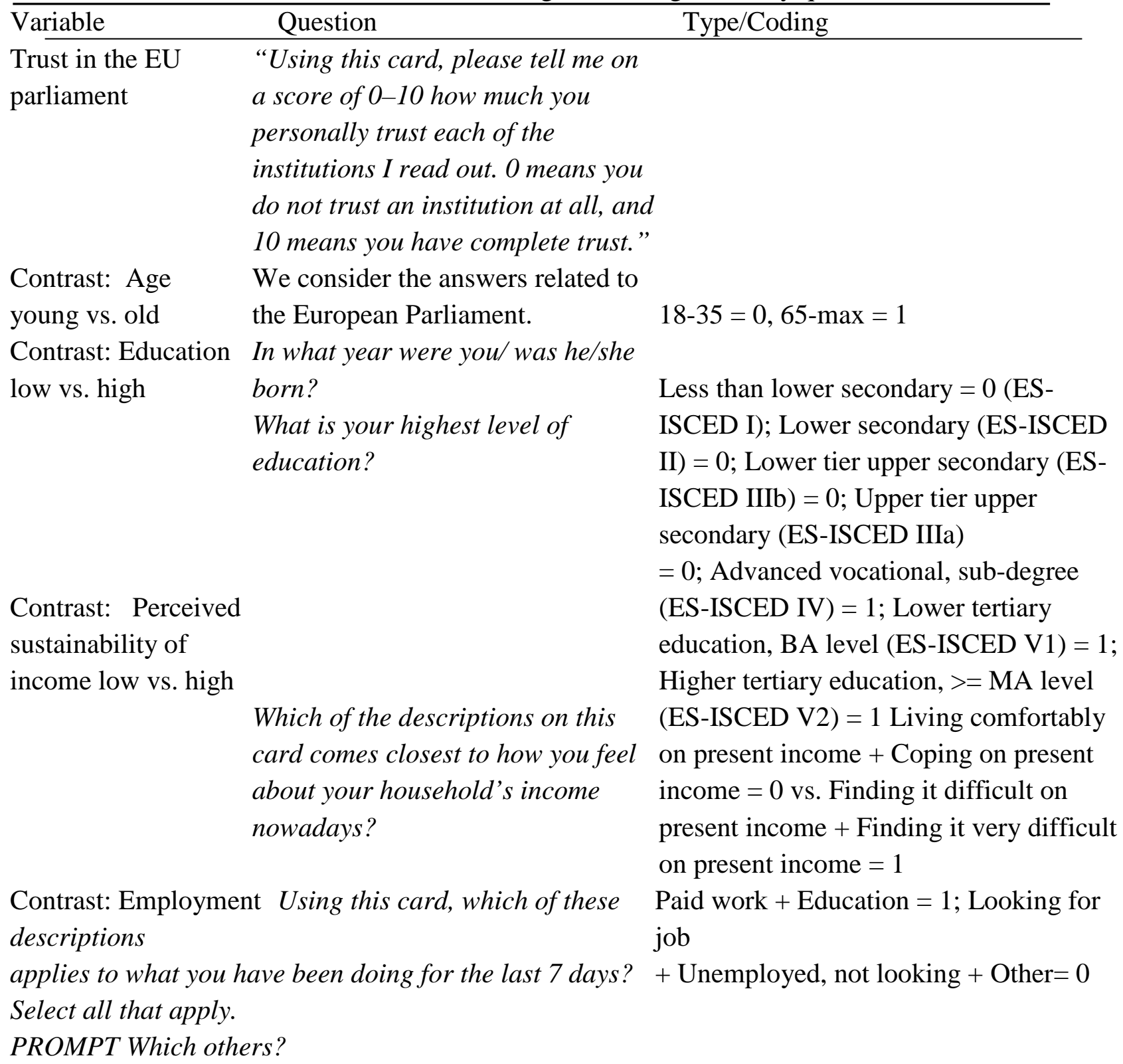


Figure A1: Covariate distributions in the sample
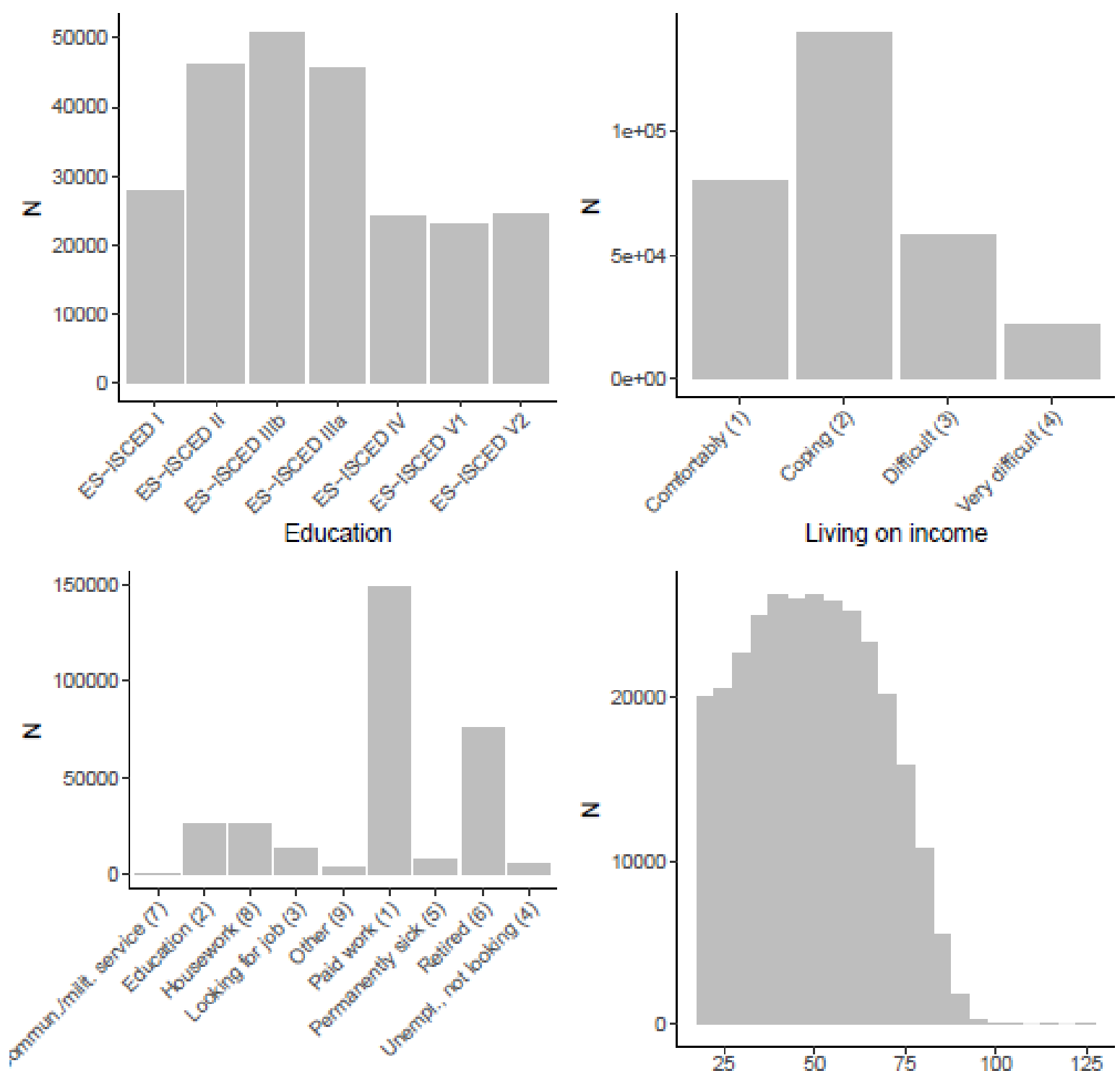

Work status

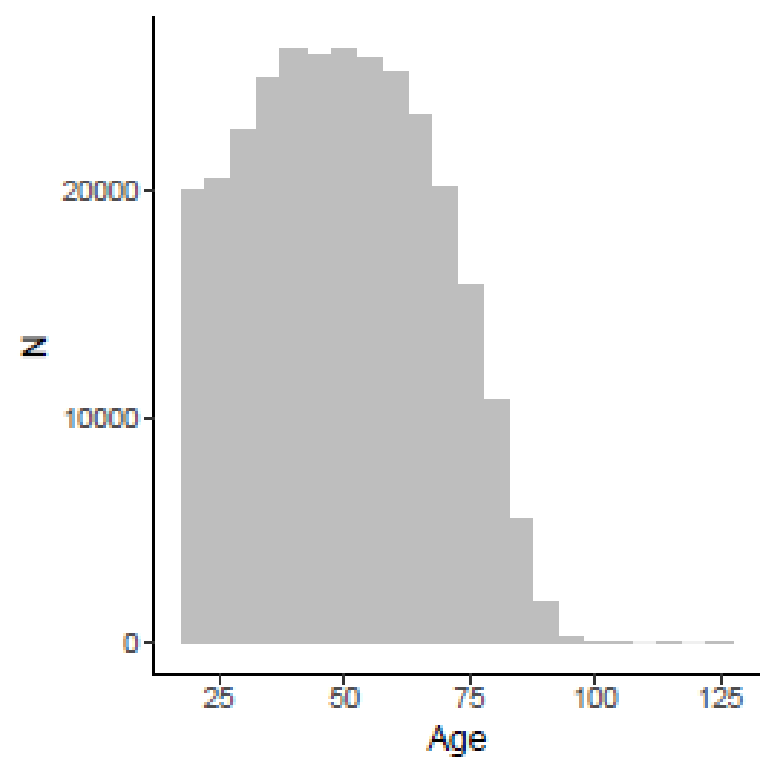




\section{A.2 Summary statistics}

Table A2: Summary of country level data

\begin{tabular}{|c|c|c|c|c|c|}
\hline Statistic & $\mathrm{N}$ & Mean & St. Dev. & Min & Max \\
\hline Year & 1592 & $2,008.93$ & 4.45 & 2,002 & 2,016 \\
\hline Trust euparliament mean & 159 & 4.51 & 0.60 & 2.56 & 6.00 \\
\hline Trust euparliament mean w sdm & 157 & 4.53 & 0.58 & 2.59 & 5.96 \\
\hline Trust euparliament var & 159 & 5.77 & 0.97 & 3.72 & 10.16 \\
\hline Trust euparliament var w sdm & 157 & 5.79 & 0.98 & 3.67 & 10.33 \\
\hline Trust euparliament missings & 159 & 186.09 & 111.97 & 15 & 659 \\
\hline Trust parliament mean & 159 & 4.29 & 1.05 & 1.88 & 6.50 \\
\hline Trust parliament var & 159 & 5.46 & 0.73 & 3.64 & 7.56 \\
\hline Trust parliament missings & 159 & 50.55 & 33.74 & 3 & 219 \\
\hline Periphery & 159 & 0.23 & 0.42 & 0 & 1 \\
\hline Time 2006 dummy & 159 & 0.63 & 0.48 & 0 & 1 \\
\hline Time 2008 dummy & 159 & 0.49 & 0.50 & 0 & 1 \\
\hline Unemployment & 159 & 8.52 & 3.93 & 2.55 & 24.79 \\
\hline Gdp growth & 159 & 2.32 & 2.68 & -5.48 & 11.89 \\
\hline Year rescaled & 159 & 6.93 & 4.45 & 0 & 14 \\
\hline Overlap age & 159 & 0.78 & 0.08 & 0.57 & 0.94 \\
\hline Overlap hincome & 157 & 0.78 & 0.06 & 0.61 & 0.93 \\
\hline Overlap paid work & 159 & 0.81 & 0.07 & 0.63 & 0.92 \\
\hline Overlap age young middle & 159 & 0.81 & 0.07 & 0.61 & 0.95 \\
\hline Overlap age middle old & 159 & 0.87 & 0.04 & 0.72 & 0.95 \\
\hline Overlap education eisced & 126 & 0.80 & 0.07 & 0.54 & 0.95 \\
\hline Meandiff age & 159 & 0.55 & 0.35 & 0.002 & 1.56 \\
\hline Meandiff hincome & 157 & 0.62 & 0.24 & 0.03 & 1.34 \\
\hline Meandiff paid work & 159 & 0.40 & 0.27 & 0.002 & 1.06 \\
\hline Meandiff age young middle & 159 & 0.46 & 0.27 & 0.0002 & 1.17 \\
\hline Meandiff age middle old & 159 & 0.18 & 0.16 & 0.001 & 0.82 \\
\hline Meandiff education eisced & 126 & 0.49 & 0.24 & 0.01 & 1.07 \\
\hline
\end{tabular}




\section{A.3 Alternative specifications: overall polarization}

Table A3 replicates the analysis included in Table 2 using weighted mean and variance.

Table A3: changes in trust in the EP (weighted mean and variance) over time

\begin{tabular}{lcccc}
\hline & \multicolumn{4}{c}{ Outcome: trust in the EP } \\
\cline { 2 - 5 } & M1 & Mean & M3 & M4 \\
\hline Year (0-14) & $-0.04^{* * *}$ & $-0.03^{* *}$ & $0.04^{* * *}$ & $0.02^{*}$ \\
& $(0.01)$ & $(0.01)$ & $(0.01)$ & $(0.01)$ \\
Periphery (0,1) & & $1.08^{* * *}$ & & $-1.46^{* * *}$ \\
Year x Periphery & & $(0.24)$ & $(0.29)$ \\
Constant & & $-0.07^{* * *}$ & & $0.07^{* *}$ \\
& $4.24^{* * *}$ & $(0.02)$ & & $(0.02)$ \\
\hline Observations & $(0.19)$ & $\left(0.14^{* * *}\right.$ & $6.31^{* * *}$ & $6.41^{* * *}$ \\
$\mathrm{R}^{2}$ & 157 & 157 & $(0.22)$ & $(0.21)$ \\
\hline Note: & 0.60 & 0.65 & 157 & 157 \\
& & & 0.80 & 0.82 \\
\hline
\end{tabular}

Table A4 replicates the analysis included in Table 2 using weighted mean and variance as well as a different specification of the time variable coded as a pre-post crisis dummy, with a value of 1 corresponding to the years after 2008 and a value of 0 otherwise.

Table A4: changes in trust in the EP (different time specification) over time Outcome: trust in the EP

\begin{tabular}{lcccc}
\cline { 2 - 4 } & \multicolumn{2}{c}{ Mean } & \multicolumn{2}{c}{ Variance } \\
& M2 & M3 & M4 \\
\hline Post-crisis (after 2008) & $-0.43^{* * *}$ & $-0.25^{* * *}$ & $0.34^{* * *}$ & $0.19^{*}$ \\
& $(0.06)$ & $(0.07)$ & $(0.08)$ & $(0.08)$ \\
Periphery (0,1) & & $1.05^{* * *}$ & & $-1.19^{* * *}$ \\
& & $(0.21)$ & & $(0.27)$ \\
Post-crisis x Periphery & & $-0.75^{* * *}$ & $0.61^{* * *}$ \\
& & $(0.13)$ & & $(0.17)$
\end{tabular}




\begin{tabular}{lcccc} 
Constant & $\begin{array}{c}4.06^{* * *} \\
(0.17)\end{array}$ & $\begin{array}{c}3.98^{* * *} \\
(0.16)\end{array}$ & $\begin{array}{c}6.31^{* * *} \\
(0.21)\end{array}$ & $\begin{array}{c}6.37^{* * *} \\
(0.20)\end{array}$ \\
\hline Observations & 159 & 159 & 159 & 159 \\
$\mathrm{R}^{2}$ & 0.66 & 0.72 & 0.81 & 0.82 \\
\hline Note: & \multicolumn{4}{c}{$\mathrm{p}<0.05 ;{ }^{* *} \mathrm{p}<0.01 ;{ }^{* * *} \mathrm{p}<0.001$} \\
& Data: European Social Survey, 2002-2016. \\
& The models include country fixed effects.
\end{tabular}


Table A5 and A6 re-estimate the models in Table 2, adding yearly measures of unemployment and gdp growth as control variables.

Table A5: Time trend: controlling for unemployment and gdp growth

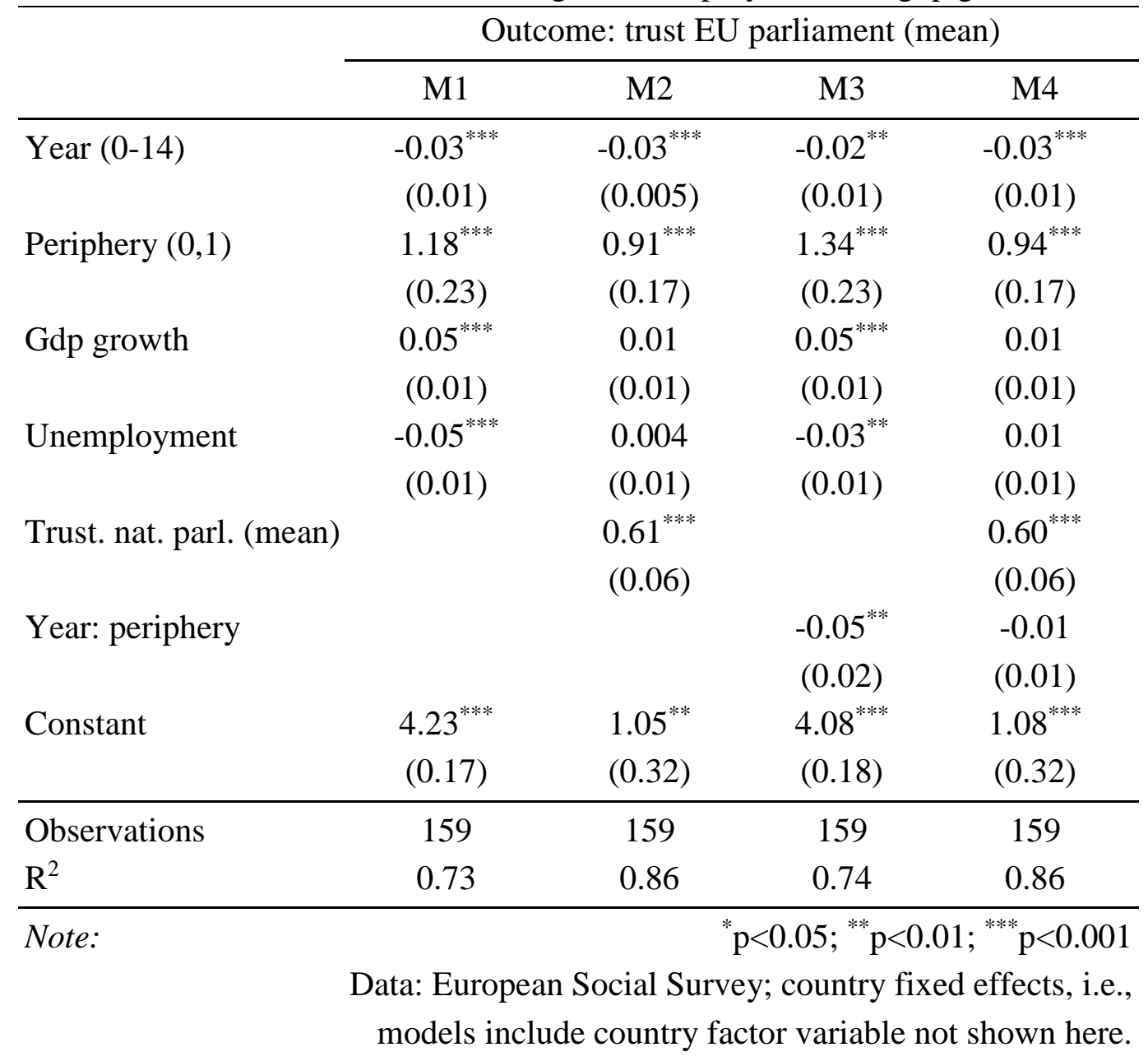


Table A6: Time trend: controlling for unemployment and gdp growth

\begin{tabular}{|c|c|c|c|c|}
\hline & \multicolumn{4}{|c|}{ Outcome: trust EU parliament (var.) } \\
\hline & M1 & M2 & M3 & M4 \\
\hline \multirow[t]{2}{*}{ Year (0-14) } & $0.04^{* * *}$ & $0.02^{*}$ & $0.03^{* *}$ & 0.01 \\
\hline & $(0.01)$ & $(0.01)$ & $(0.01)$ & $(0.01)$ \\
\hline \multirow[t]{2}{*}{ Periphery $(0,1)$} & $-1.41^{* * *}$ & $-1.27^{* * *}$ & $-1.57^{* * *}$ & $-1.40^{* * *}$ \\
\hline & $(0.29)$ & $(0.24)$ & $(0.29)$ & $(0.25)$ \\
\hline \multirow[t]{2}{*}{ Gdp growth } & $0.03^{*}$ & 0.02 & $0.03^{*}$ & 0.02 \\
\hline & $(0.02)$ & $(0.01)$ & $(0.02)$ & $(0.01)$ \\
\hline \multirow[t]{2}{*}{ Unemployment } & $0.05^{* * *}$ & $0.05^{* * *}$ & $0.03^{*}$ & $0.03^{* *}$ \\
\hline & $(0.01)$ & $(0.01)$ & $(0.01)$ & $(0.01)$ \\
\hline \multirow[t]{2}{*}{ Trust. nat. parl. (var.) } & & $0.50^{* * *}$ & & $0.49^{* * *}$ \\
\hline & & $(0.07)$ & & $(0.07)$ \\
\hline \multirow[t]{2}{*}{ Year x Periphery } & & & $0.05^{*}$ & $0.04^{*}$ \\
\hline & & & $(0.02)$ & $(0.02)$ \\
\hline \multirow[t]{2}{*}{ Constant } & $5.86^{* * *}$ & $3.11^{* * *}$ & $6.01^{* * *}$ & $3.28^{* * *}$ \\
\hline & $(0.22)$ & $(0.42)$ & $(0.23)$ & $(0.42)$ \\
\hline Observations & 159 & 159 & 159 & 159 \\
\hline $\mathrm{R}^{2}$ & 0.83 & 0.88 & 0.84 & 0.89 \\
\hline \multirow[t]{2}{*}{ Note: } & \multicolumn{4}{|c|}{${ }^{*} \mathrm{p}<0.05 ;{ }^{* *} \mathrm{p}<0.01 ;{ }^{* * *} \mathrm{p}<0.001$} \\
\hline & a: Eu & 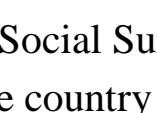 & country & effects, i.e. \\
\hline
\end{tabular}


Below, we depict trends of mean and variance for national-level parliaments alongside the same trends for trust in the EP.

Figure A2: changes in trust in the EP and trust in national parliaments over time

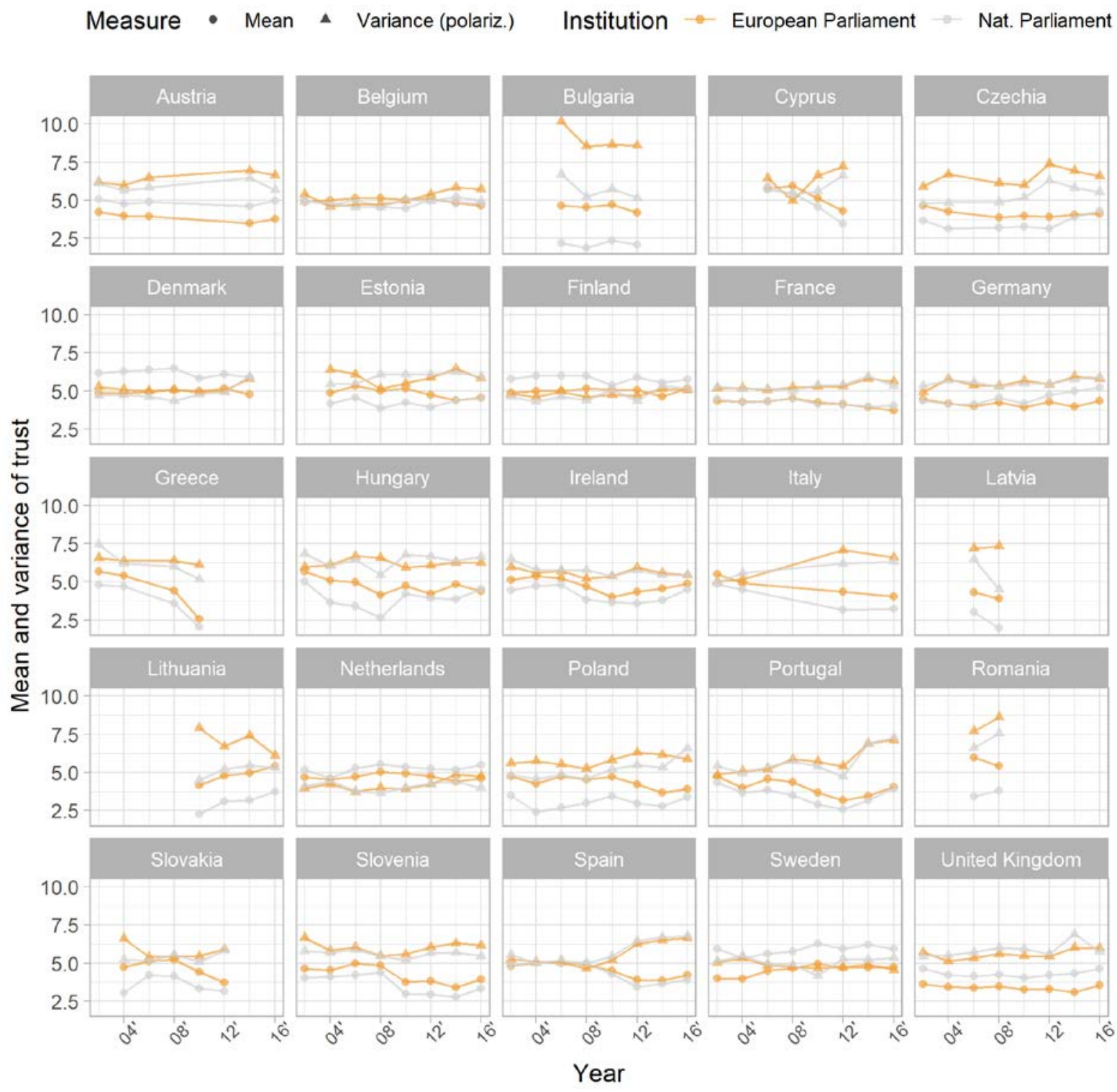




\section{A.4 Alternative specifications: between-group polarization}

Table A7: Between-group polarization (mean difference): time trend

\begin{tabular}{|c|c|c|c|c|c|c|c|c|}
\hline & \multicolumn{8}{|c|}{ Outcome: mean difference } \\
\hline & \multicolumn{2}{|c|}{ Age groups } & \multicolumn{2}{|c|}{ Income groups } & \multicolumn{2}{|c|}{ Work groups } & \multicolumn{2}{|c|}{ Educ. groups } \\
\hline & M1 & M2 & M3 & M4 & M5 & M6 & M7 & M8 \\
\hline \multirow[t]{2}{*}{ Year $(0-14)$} & $0.02^{* * *}$ & $0.02^{* * *}$ & $0.01^{* *}$ & $0.01^{*}$ & $0.01^{* *}$ & $0.01^{* *}$ & -0.01 & -0.01 \\
\hline & $(0.004)$ & $(0.005)$ & $(0.004)$ & $(0.004)$ & $(0.004)$ & $(0.004)$ & $(0.004)$ & $(0.004)$ \\
\hline \multirow[t]{2}{*}{ Periphery $(0,1)$} & & $-0.49^{* * *}$ & & -0.18 & & -0.16 & & $-0.60^{* * *}$ \\
\hline & & $(0.14)$ & & $(0.13)$ & & $(0.13)$ & & $(0.16)$ \\
\hline \multirow[t]{2}{*}{ Year x Periphery } & & 0.01 & & 0.01 & & -0.01 & & -0.0002 \\
\hline & & $(0.01)$ & & $(0.01)$ & & $(0.01)$ & & $(0.01)$ \\
\hline \multirow[t]{2}{*}{ Constant } & $0.47^{* * *}$ & $0.49^{* * *}$ & $0.49^{* * *}$ & $0.51^{* * *}$ & $0.41^{* * *}$ & $0.39^{* * *}$ & $0.80^{* * *}$ & $0.80^{* * *}$ \\
\hline & $(0.10)$ & $(0.10)$ & $(0.09)$ & $(0.09)$ & $(0.10)$ & $(0.10)$ & $(0.12)$ & $(0.13)$ \\
\hline Observations & 159 & 159 & 157 & 157 & 159 & 159 & 126 & 126 \\
\hline $\mathrm{R}^{2}$ & 0.67 & 0.67 & 0.43 & 0.44 & 0.49 & 0.50 & 0.63 & 0.63 \\
\hline Note: & & & & & ${ }^{*} \mathrm{p}$ & $5{ }^{* *}$ & .01 & $<0.00$ \\
\hline
\end{tabular}

Table A8: Between-group polarization trend: other age group specifications Outcome: overlap coefficient

\begin{tabular}{|c|c|c|c|c|}
\hline & \multicolumn{4}{|c|}{ Outcome: overlap coefficient } \\
\hline & \multicolumn{4}{|c|}{ Age groups (young/middle) Age groups (middle/old) } \\
\hline & M1 & M2 & M3 & M4 \\
\hline \multirow[t]{2}{*}{ Year (0-14) } & $-0.003^{* *}$ & $-0.002^{*}$ & 0.0003 & 0.001 \\
\hline & $(0.001)$ & $(0.001)$ & $(0.001)$ & $(0.001)$ \\
\hline \multirow[t]{2}{*}{ Periphery $(0,1)$} & & $0.10^{* * *}$ & & 0.02 \\
\hline & & $(0.03)$ & & $(0.03)$ \\
\hline \multirow[t]{2}{*}{ Year x Periphery } & & -0.002 & & $-0.004^{*}$ \\
\hline & & $(0.002)$ & & $(0.002)$ \\
\hline \multirow[t]{2}{*}{ Constant } & $0.78^{* * *}$ & $0.78^{* * *}$ & $0.85^{* * *}$ & $0.85^{* * *}$ \\
\hline & $(0.02)$ & $(0.02)$ & $(0.02)$ & $(0.02)$ \\
\hline Observations & 159 & 159 & 159 & 159 \\
\hline $\mathrm{R}^{2}$ & 0.66 & 0.66 & 0.18 & 0.21 \\
\hline Note: & & & ${ }^{* *} \mathrm{p}<$ & ${ }^{*} \mathrm{p}<$ \\
\hline
\end{tabular}


Figure A3: Between-group polarization (mean difference): time trend

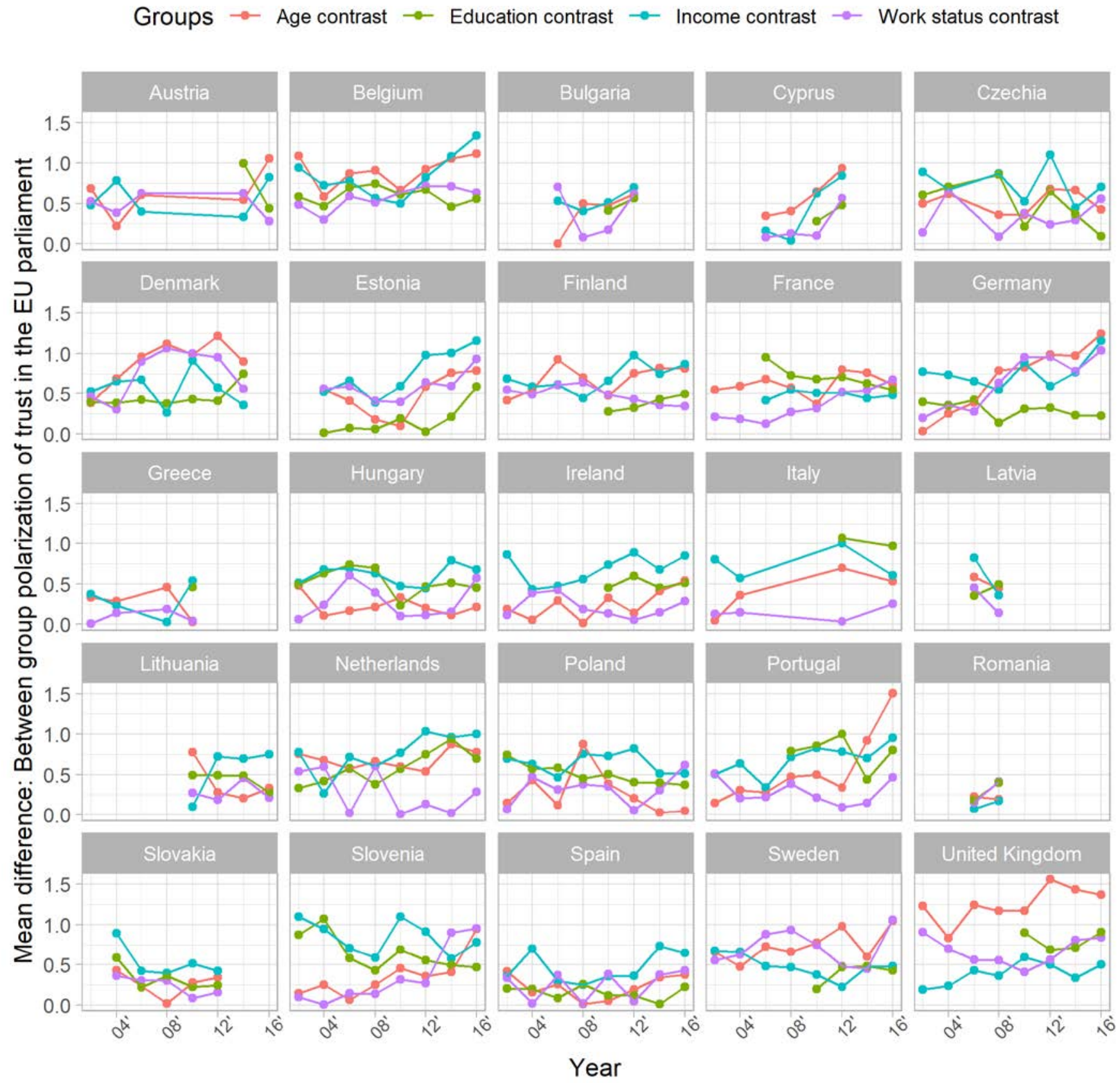

